\title{
Sex-specific associations between cortisol and birth weight in pregnancies complicated by asthma are not due to differential glucocorticoid receptor expression
}

\author{
Nicolette A Hodyl, ${ }^{1}$ Hayley Wyper, ${ }^{2}$ Annette Osei-Kumah, ${ }^{1}$ Naomi Scott, ${ }^{2}$ \\ Vanessa E Murphy, ${ }^{3}$ Peter Gibson, ${ }^{3}$ Roger Smith, ${ }^{2}$ Vicki L Clifton ${ }^{1}$
}

${ }^{1}$ The Robinson Institute, Discipline of Obstetrics and Gynaecology, University of Adelaide, South Australia, Australia

${ }^{2}$ Mothers and Babies Research Centre, Hunter Medical Research Institute, University of Newcastle, New South Wales, Australia

${ }^{3}$ Department of Respiratory and Sleep Medicine, Hunter Medical Research Institute, University of Newcastle, New South Wales, Australia

\section{Correspondence to}

Vicki Clifton, The Robinson Institute, Discipline of Obstetrics and Gynaecology, University of Adelaide, Level 6, Medical School North, Frome Road, Adelaide SA 5005, Australia vicki.clifton@adelaide.edu.au

Received 7 July 2009

Accepted 21 May 2010

\begin{abstract}
Background Fetal growth inhibition is a known sequelae of in utero glucocorticoid exposure and has long-term consequences for adult health. Sex-specific fetal growth patterns are observed in pregnancies with maternal asthma and may be due to differential sensitivity of the placenta to glucocorticoids. It is currently unknown whether expression of the placental glucocorticoid receptor (GR) becomes altered with asthma or the use of inhaled corticosteroids.
\end{abstract}

Methods Pregnant women with mild asthma $(n=52)$, moderate-severe asthma $(n=71)$ and without asthma $(n=51)$ were recruited at John Hunter Hospital, Newcastle, Australia. At delivery, placentae and cord blood were collected, and fetal sex and birth weight were recorded. Placental GR heterogeneous nuclear RNA (hnRNA), mRNA and protein were measured and cord blood cortisol concentrations were assessed.

Results Placental GR gene activity increased with cortisol exposure but decreased with inhaled corticosteroid treatment $(p=0.05)$. With maternal asthma, female birth weight centiles were inversely associated with cortisol $(r=-0.286, p=0.017)$ and, despite a decrease in placental GR mRNA $(p=0.003)$, placental GR $\alpha$ protein levels were unchanged. In males, no change to cortisol, birth weight or placental GR were evident in pregnancies with asthma. Together, these results indicate that in pregnancies complicated by asthma, placental GR gene activity, but not mRNA expression or protein levels, is dependent on cortisol and inhaled corticosteroid treatment.

Conclusions The sex-specific associations between cortisol and birth weight observed in pregnancies with asthma are not due to altered GR expression; however, they may be due to differential glucocorticoid sensitivity via preferential transcription of GR isoforms or posttranslational modifications.

\section{INTRODUCTION}

With the increasing prevalence of childhood allergy and atopic disease worldwide, an urgent need has arisen to understand in utero mechanisms that predispose infants towards this outcome. These mechanisms are currently unknown; however, the contribution of maternal asthma and atopy during pregnancy to wheeze and atopic symptoms in childhood is in the preliminary stages of investigation. ${ }^{1}{ }^{2}$ Retrospective studies have indicated that maternal atopy alters feto-placental immune mechanisms, with cord blood cytokine concentrations skewed towards a type $2 \mathrm{~T}$ helper profile. ${ }^{3-5}$
Ongoing work from our laboratory has demonstrated that the effects of maternal asthma during pregnancy on feto-placental immunity are dependent on asthma severity and use of inhaled corticosteroids (ICS) for asthma treatment, and differ according to fetal sex. ${ }^{6-9}$ Further, maternal asthma is associated with a reduction in female birth weight, ${ }^{9}$ and low birth weight has been independently linked to other adverse health outcomes in both children and adults. ${ }^{10}$

Animal and human studies indicate that fetal growth is reduced following excess exposure to glucocorticoids (for a review, see Seckl and Holmes $\left.{ }^{11}\right)$. This appears to be an important factor driving the sex-specific reduction in birth weight that we have previously reported in pregnancies complicated by asthma. Specifically, an asthmainduced reduction in the placental cortisol-metabolising enzyme, $11 \beta$ hydroxysteroid dehydrogenase type $2(11 \beta-H S D 2)$ was associated with reduced female birth weights. ${ }^{9}$ This reduction in $11 \beta$-HSD2 activity increases exposure of the female fetus to cortisol. In these studies, the use of ICS to manage asthma restored female birth weight centiles to control levels and normalised 11ß-HSD2 activity. ${ }^{12}$ The protective effect on female birth weight conferred by ICS treatment for maternal asthma may be due to sexually dimorphic alterations in placental glucocorticoid responsiveness.

Responsiveness to glucocorticoids is mediated both centrally and peripherally by the glucocorticoid receptor (GR), of which there are multiple isoforms. ${ }^{13}$ We have previously identified the presence of four GR isoforms in the placenta: GR $\alpha, G R \beta$, GR $\gamma$ and GR-P, although the latter was only identifiable in a subset of placentae. ${ }^{14}$ The most predominant mature isoform expressed was GR $\alpha$, consistent with its ubiquitous expression throughout the body. This isoform mediates the functional biological effects of glucocorticoids, including cell growth, proliferation and differentiation (for a review, see Pujols et $a 1^{15}$ ), and our studies have indicated that its expression in the placenta becomes inhibited following in vitro glucocorticoid exposure. ${ }^{14}$ The actions of other GR isoforms also determine functional responses to glucocorticoids: GR $\beta$ is a dominant inhibitor of GR $\alpha$ binding, ${ }^{16} \mathrm{GR}-\mathrm{P}$ enhances GR $\alpha$ transcription ${ }^{17}$ and GR $\gamma$ plays a role in mediating glucocorticoid resistance in childhood acute lymphoblastic leukaemia. ${ }^{18}$

The placental response to glucocorticoids appears crucial in determining fetal growth outcomes. Exposure to synthetic glucocorticoids during 
pregnancy is associated with reductions in birth weight in a number of animal models, ${ }^{19-22}$ which often appear sex specific ${ }^{2324}$; however, data from comparable human studies remain inconclusive. ${ }^{25-27}$ Functional responses to glucocorticoids are determined in part by the relative expression of the different GR isoforms, which are altered through exposure to glucocorticoids. ${ }^{28}$ This is an important consideration in the study of placental GR regulation in pregnant women with asthma, as circulating endogenous cortisol increases with asthma severity ${ }^{29}$ and asthma is often managed with inhaled or oral steroids. This study will therefore assess the effects of endogenous cortisol and ICS on in vivo GR expression in the delivered placenta and its relationship to birth weight. The aims of this study were (1) to identify whether maternal asthma was associated with differences in transcription and translation of placental GR mRNA and GR protein expression; (2) to identify whether ICS treatment affects regulation of the placental GR; and (3) to identify sex-specific relationships between birth weight centiles and GR protein expression in asthmatic and control pregnancies.

\section{METHODS}

\section{Participants}

Ethics approval was gained from the Hunter New England Health and the University of Newcastle Human Research Ethics Committees. We have previously reported maternal and fetal characteristics of a cohort of pregnant women recruited into our asthma studies ${ }^{91230}$ and have reported an adherence rate to ICS treatment of $80 \%{ }^{31}$ The current data correspond to a subset of this cohort, where we were able to collect placenta and venous cord blood with $45 \mathrm{~min}$ of delivery. Power analyses were conducted using Power and Precision Software, ensuring a power of $80 \%$ and $\alpha$ of 0.05 , based on variability observed in our previous findings. ${ }^{14}$ Control women without asthma $(n=51)$ and women with asthma $(n=123)$ were recruited at their first antenatal visit to the John Hunter Hospital (Newcastle, NSW, Australia). Asthma severity was assessed as described previously, ${ }^{31}$ and graded as mild, moderate or severe at 12, 18 and 30 weeks gestation. ${ }^{31}$ Participants were grouped according to the most severe grade of asthma experienced during pregnancy, as previously reported. ${ }^{32} 33$

Given that cigarette smoking can affect birth weight and attenuate cortisol levels, ${ }^{34}$ participant self-report of cigarette smoking was recorded from antenatal records and following interview at recruitment. Birth weight and length were recorded and converted into centiles using growth charts ${ }^{35}$ and a birth centile calculator (http://www.gestation.net/; Perinatal Institute, UK), with birth centiles $<10$ defined as small for gestational age (SGA).

\section{Placental tissue preparation, RNA isolation and real-time reverse transcription-PCR (RT-PCR) analysis}

Placental tissue samples were pooled from six cotyledons, blotted to remove blood, snap-frozen and stored at $-80^{\circ} \mathrm{C}$. Pooling of tissue removes variability across sites on the placenta. Total RNA was extracted from $0.2 \mathrm{~g}$ of crushed frozen placenta using the TRIzol method (Invitrogen, Mt Waverley, Australia), as described previously. ${ }^{14}$ Quantitative real-time RT-PCR was used to determine mRNA abundance of total GR, GR $\alpha$, GR exon $1 \mathrm{~A} 3$ and GR heterogeneous nuclear RNA (hnRNA) in placental samples compared with levels of the housekeeping gene, $\beta$-actin. GR hnRNA is the precursor of GR mRNA and thus serves as a reliable surrogate marker of gene activity in both fresh tissue and cultured cells. ${ }^{36} 37$ The real-time RT-PCR protocol, primer sequences and optimal concentrations were identical to those reported previously. ${ }^{14}$ All samples were assayed in triplicate and variability in mRNA expression was $<5 \%$.

\section{Protein extraction and western blot analysis}

Placental tissue was homogenised and protein extracted as described previously. ${ }^{12}$ Extracted protein samples were prepared by combining extract $(20 \mu \mathrm{g})$ with $5 \mu \mathrm{l}$ of NuPAGE lithium dodecyl sulfate (LDS) sample buffer. Samples were heated for $12 \mathrm{~min}$ at $70^{\circ} \mathrm{C}$ and $2 \mu \mathrm{l}$ of NuPAGE reducing agent (Invitrogen, Life Technologies, Carlsbad, California, USA) was added. Protein samples $(20 \mu \mathrm{g} / \mathrm{lane})$ were separated by electrophoresis through $7 \%$ Tris-acetate precast gels on an Xcell SureLock Electrophoresis cell (Invitrogen). Gels were run at $150 \mathrm{~V}$ for $1 \mathrm{~h}$ in a Tris-acetate running buffer with $500 \mu \mathrm{l}$ of NuPAGE antioxidant (Invitrogen) in the inner chamber. Proteins were electrophoretically transferred to $0.45 \mu \mathrm{m}$ pore nitrocellulose membranes (Hybond-C Extra, Amersham Biosciences, UK) at $30 \mathrm{~V}$ for $1 \mathrm{~h}$. Transfer membranes were incubated overnight with $5 \%$ skim milk in blocking solution (Tris-buffered saline (TBS) with 5\% skim milk powder). Blots were incubated for $2 \mathrm{~h}$ at room temperature with 1:200 dilution of the primary antibody in blocking solution. For detection of $\mathrm{GR} \alpha$ protein, an affinity-purified rabbit polyclonal immunoglobulin G (IgG) antibody was used (Santa Cruz Biotechnology, Santa Cruz, California, USA). Blots were incubated for $1 \mathrm{~h}$ at room temperature with a horseradish peroxidase-labelled goat antirabbit secondary antibody provided with the ECL kit (Pierce Biotechnology, Rockford, Illinois, USA). Signal detection of antibody complexes was performed using Pierce Supersignal Dura Extended Duration Substrate (Pierce Biotechnology) as per the manufacturer's instructions. Densitometric analysis (Multi Gauge V2.4) was used to quantify the intensity of the protein signals relative to a $38 \mathrm{kDa}$ band to which the secondary antibody bound, to adjust for loading (figure 1). We identified that the $38 \mathrm{kDa}$ band changed with protein concentration in our optimisation studies and we have

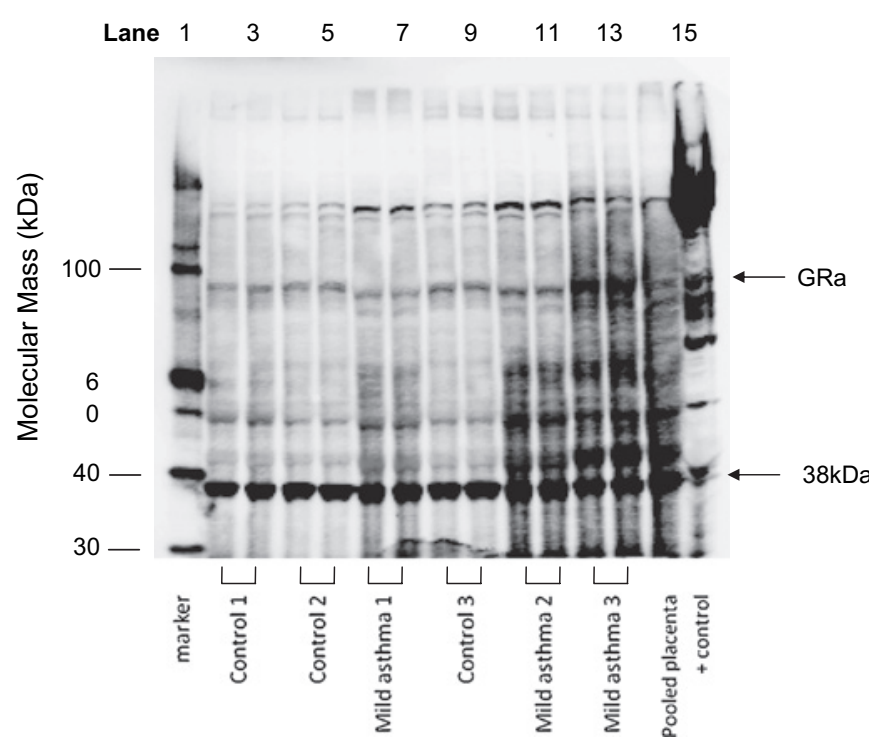

Figure 1 Representative western blot of placental protein samples, indicating the $95 \mathrm{kDa}$ band corresponding to glucorticoid receptor $\alpha(\mathrm{GR} \alpha)$ and the position of the $38 \mathrm{kDa}$ reference band. Lane 1 is the molecular weight marker; lanes $2-13$ are placental protein samples in duplicate (lanes 2-5, 8 and 9 are placentae samples from controls; lanes $6,7,10-13$ are placentae samples from women with mild asthma; lane 14 is a positive control (pooled placental sample); lane 15 is a positive control (rat brain). 
previously used this method as a control for loading variations. ${ }^{9}$ Each blot contained a positive control (rat brain protein extract) and an interassay control (pooled placental sample).

\section{Plasma collection and cortisol radioimmunoassay (RIA)}

Plasma was separated from cord blood via centrifugation. Cortisol concentrations were determined in duplicate in plasma collected from the placental umbilical vein, using a commercial RIA kit (Diagnostic Systems Laboratories, Webster, Texas, USA) following the manufacturer's instructions. The detection limit was $4.7 \mathrm{nmol} / 1$; the intra-assay variation was $5.1 \%$ and crossreactivity of cortisol antiserum with other steroids was $<0.1 \%$.

\section{Statistical analysis}

Statistics were performed using the Statistical Package for the Social Sciences (SPSS v 17; SPSS, Chicage, Illinois, USA). An a priori decision was made to analyse the data separately by sex when comparing the effects of asthma severity and treatment, as past research indicates that placental cortisol metabolism differs between males and females in the presences of asthma. ${ }^{8} 12$ The abundance of GR hnRNA and mRNA transcripts was log (natural) transformed to normalise the data. To assess the effect of asthma severity and asthma treatment on protein and mRNA expression abundance, one-way analysis of variance (ANOVA) was used with Tukey post hoc testing where indicated. Student $t$ tests and Mann-Whitney $U$ tests were used for comparisons made between two normally and non-normally distributed variables, respectively. Pearson correlations were performed to assess associations between the log-transformed expression data, birth weight centiles and cortisol concentrations. Frequencies of maternal smoking and SGA births in the control and asthma groups were analysed using $\chi^{2}$. $p$ Values $\leq 0.05$ were considered statistically significant.

\section{RESULTS}

\section{Maternal and neonatal characteristics}

The maternal and neonatal characteristics are reported according to both asthma severity and asthma treatment in tables 1 and 2, respectively. Maternal age was significantly higher in the control population than both the populations with asthma $(\mathrm{F}(2,171)=$ 8.715, $\mathrm{p}<0.001)$. Maternal forced expiratory volume in $1 \mathrm{~s}$ $\left(\mathrm{FEV}_{1}\right)$ was significantly lower in the moderate-severe asthma group compared with the control and mild asthma groups ( $F$ $(2,171)=3.225, p=0.043)$, but did not differ according to asthma treatment $(p=0.100)$. More women with asthma smoked (33.8\%) compared with controls $\left(5.9 \% ; \chi^{2}=13.364, p=0.001\right)$.

Male birth weight centiles were significantly greater than those of females $(t(173)=2.78, p=0.006)$. Female birth weight, birth weight centile, length, and abdominal and head circumferences were not different between the groups. In females, cord blood cortisol was significantly increased in the moderate-severe asthma group compared with the controls and the mild asthma groups $(\mathrm{F}(2,67)=3.2, \mathrm{p}=0.047)$, and negatively correlated with birth weight centiles $(r=-0.286, p=0.017$, $\mathrm{n}=69$ ). Significantly more females were born SGA in the group with moderate-severe asthma $(22.5 \%)$ than in both the control $(9.5 \%)$ and the mild asthma (3.2\%) groups $\left(\chi^{2}=6.018, p=0.049\right)$. In male neonates, no difference was observed in birth weight centiles or cortisol between the control and asthma treatment groups, and the two were not correlated. Frequency rates of male infants born SGA did not differ between the control and asthma groups. Length centiles were significantly reduced in the moderate-severe asthma group compared with the control and mild asthma groups $(\mathrm{F}(2,54)=4.159, \mathrm{p}=0.021)$.

\section{The effect of asthma on placental GR gene activity, mRNA expression and protein levels}

Placental GR gene activity (as measured through hnRNA expression) was significantly increased in the group with mild asthma compared with both the moderate-severe asthma group and the controls $(\mathrm{F}(2,113)=2.91, \mathrm{p}=0.049$; figure 2$)$. Total $\mathrm{GR}$ and GR $\alpha$ mRNA were unaffected by asthma, regardless of severity (figure 2).

Expression of GR hnRNA was correlated with cord blood cortisol in the control $(r=0.458, p=0.008)$ and in the moderate-severe asthma groups $(r=0.327, p=0.030)$, but not in the mild group. GR hnRNA was positively correlated with exon $1 \mathrm{~A} 3$ in the mild $(r=0.703, p<0.001)$ and the moderate-severe asthma group $(r=0.851, p<0.001)$, but not in the control group. Cord blood cortisol levels were positively correlated with GR $\alpha$ protein in the mild asthma group only $(r=0.552, p=0.012)$. In both the control and asthma groups, GR $\alpha$ protein was not correlated with any GR mRNA transcript or birth weight centiles.

Table 1 Maternal characteristics of the study populations according to asthma treatment and asthma severity

\begin{tabular}{|c|c|c|c|c|c|c|c|}
\hline & \multirow[b]{2}{*}{ Control } & \multicolumn{3}{|l|}{ Asthma treatment } & \multicolumn{3}{|l|}{ Asthma severity } \\
\hline & & No treatment & Inhaled corticosteroids & p Value & Mild & Moderate-severe & p Value \\
\hline $\mathrm{n}$ & 51 & 52 & 71 & & 58 & 65 & \\
\hline Height (cm) & $164.2(162.2$ to 165.9$)$ & 164.1 (161.8 to 166.1 ) & $164.0(162.7$ to 165.8$)$ & 0.99 & $163.4(162.0$ to 166.0$)$ & $164.4(162.6$ to 165.8$)$ & 0.81 \\
\hline Weight (early) (kg) & 73.9 (65.0 to 77.4$)$ & 76.9 (69.2 to 81.1 & $75.3(69.8$ to 81.3$)$ & 0.80 & 77.4 (68.9 to 80.7$)$ & 74.7 (70.0 to 81.6$)$ & 0.67 \\
\hline Weight (late) (kg) & 83.0 (76.6 to 87.9 ) & 88.3 (81.7 to 92.9 & 85.4 (80.5 to 91.2 ) & 0.47 & 88.1 (82.2 to 92.8 ) & 85.3 (80.2 to 91.2 ) & 0.47 \\
\hline Parity (median, range) & $1(0-6)^{*}$ & $0(0-4)$ & $1(0-6)$ & 0.011 & $0(0-4)$ & $1(0-6)$ & 0.004 \\
\hline $\mathrm{FEV}_{1}$ & $3.2(3.0$ to 3.4$)$ & 3.2 (3.0 to 3.3$)$ & $3.0(2.9$ to 3.2$)$ & 0.10 & $3.2(3.0$ to 3.4$)$ & $3.0(2.8$ to 3.2$) \dagger$ & 0.043 \\
\hline Vital capacity & $3.9(3.8$ to 4.1$)$ & $3.8(3.6$ to 4.0$)$ & $3.8(3.6$ to 3.9$)$ & 0.70 & $3.8(3.6$ to 3.9$)$ & $3.8(3.6$ to 3.9$)$ & 0.71 \\
\hline $\mathrm{GC}$ dose, third trimester & 0 & 0 & $1054.2(890.7$ to 1233.2$) \neq$ & $<0.001$ & 234.5 (123.8 to 350.3$) \S$ & $928.0(705.9$ to 1117.5$) \neq$ & $<0.001$ \\
\hline Smoking n (\%) & $3(5.9 \%)$ & $14(26.9 \%)$ & $20(28.2 \%)$ & 0.006 & $12(20.7 \%) \S$ & $22(33.8 \%) \S$ & 0.001 \\
\hline
\end{tabular}

Significance values represent a comparison of each asthma treatment and the control group and of each asthma severity and the control group. Data represent mean (95\% Cl) unless indicated.

*Significantly higher than the asthma groups.

†Significantly lower than the mild group.

$¥$ Significantly higher than the control and no treatment groups.

$\S$ Significantly higher than the control group.

$\mathrm{BMI}$, body mass index; $\mathrm{FEV}_{1}$, forced expiratory volume in $1 \mathrm{~s}$; GC, glucocorticoid. 
Table 2 Characteristics of female and male neonates in each study population according to asthma treatment and asthma severity

\begin{tabular}{|c|c|c|c|c|c|c|c|}
\hline & \multirow[b]{2}{*}{ Control } & \multicolumn{2}{|l|}{ Asthma severity } & \multirow[b]{2}{*}{$\begin{array}{l}p \\
\text { Value }\end{array}$} & \multicolumn{2}{|l|}{ Asthma treatment } & \multirow[b]{2}{*}{$\begin{array}{l}p \\
\text { Value }\end{array}$} \\
\hline & & Mild & Moderate-severe & & $\begin{array}{l}\text { No } \\
\text { treatment }\end{array}$ & $\begin{array}{l}\text { Inhaled } \\
\text { corticosteroids }\end{array}$ & \\
\hline \multicolumn{8}{|l|}{ Females } \\
\hline BW centile & 47.6 (33.0 to 58.2 ) & $54.5(40.7$ to 62.3$)$ & $46.4(37.2$ to 55.6$)$ & 0.25 & 50.2 (44.7 to 64.1$)$ & 46.3 (34.7 to 54.1 & 0.85 \\
\hline Length $(\mathrm{cm})$ & $51.4(49.0$ to 54.2$)$ & 50.9 (49.8 to 52.7$)$ & $50.7(49.4$ to 51.7$)$ & 0.76 & $51.4(50.2$ to 52.7$)$ & $50.3(49.1$ to 51.5$)$ & 0.25 \\
\hline Abdominal circumference (mm) & 271.6 (238.4 to 304.8 ) & 245.08 (229.0 to 261.2 ) & 264.2 (256.0 to 272.4$)$ & 0.37 & 247.1 (230.6 to 263.6 ) & 264.0 (256.5 to 271.5 ) & 0.37 \\
\hline Cord blood cortisol (mmol/l) & 202.72 (162.7 to 238.4 ) & 209.0 (171.4 to 246.5$)$ & $254.12(217.2 \text { to } 303.2)^{*}$ & $0.030 \dagger$ & 269.61 (194.7 to 294.7 ) & 240.71 (195.6 to 270.9 ) & 0.31 \\
\hline Apgar 5 & $9.3(8.9$ to 9.6$)$ & $9.1(8.8$ to 9.4$)$ & $9.3(9.1-9.4)$ & 0.60 & $9.2(8.9$ to 9.4$)$ & $9.3(8.9$ to 9.4$)$ & 0.82 \\
\hline SGA n (\%) & $2(9.5)$ & $1(3.2)$ & $9(22.5)^{*}$ & $0.049+$ & $3(9.7)$ & $7(17.5)$ & 0.54 \\
\hline \multicolumn{8}{|l|}{ Males } \\
\hline BW (g) & $\begin{array}{l}3642.0(3374.9 \text { to } \\
3803.1)\end{array}$ & $\begin{array}{l}3782.7 \text { (3555.4 to } \\
4010.1)\end{array}$ & $\begin{array}{l}3501.2 \text { (3323.1 to } \\
3706.9)\end{array}$ & 0.06 & $\begin{array}{l}3816.7 \text { (3633.6 to } \\
4007.9 \text { ) }\end{array}$ & $\begin{array}{l}3565.8 \text { (3217.3 to } \\
3637.5)\end{array}$ & 0.19 \\
\hline Head circumference $(\mathrm{cm})$ & 34.1 (33.3 to 35.2$)$ & 35.3 (34.6 to 36.4$)$ & 34.9 (34.1 to 35.7$)$ & 0.86 & 35.2 (33.9 to 36.1$)$ & $35.3(34.5$ to 35.9$)$ & 0.90 \\
\hline Abdominal circumference $(\mathrm{mm})$ & 261.6 (256.1 to 267.1$)$ & 264.1 (255.7 to 282.5$)$ & 272.6 (263.6 to 281.6 ) & 0.16 & 264.1 (256.3 to 272.0 ) & 271.1 (262.9 to 279.2 ) & 0.21 \\
\hline Cord blood cortisol (mmol/l) & 205.45 (170.4 to 241.2 ) & 233.4 (168 to 298.1$)$ & 225.05 (164 to 287.0 ) & 0.45 & 285.74 (154.7 to 302.3 ) & 251.86 (174.5 to 285.9 ) & 0.42 \\
\hline Apgar 5 & $9.5(9.2$ to 9.9$)$ & $9.1(8.9$ to 9.4$)$ & 9.1 (8.8 to 9.5$)$ & 0.17 & 9.2 (9 to 9.5$)$ & $9.1(8.8$ to 9.4$)$ & 0.11 \\
\hline SGA n (\%) & $2(6.6)$ & $1(3.7)$ & $2(7.7)$ & 0.82 & $1(4.5)$ & $2(6.5)$ & 0.94 \\
\hline
\end{tabular}

Reported $\mathrm{p}$ values represent significance level of univariate analysis of variance of asthma severity or asthma treatment group compared with the control group. Data represent mean (95\% Cl).

${ }^{*}$ Significant compared with both the control and mild asthma groups $(p<0.05)$.

†Significant main effect of asthma severity.

BW, birth weight; SGA, small for gestational age.

\section{The effect of glucocorticoid treatment on GR gene activity, mRNA expression and protein levels}

The treatment of asthma varied according to asthma severity $\left(\chi^{2}=26.73, \mathrm{df}=1, \mathrm{p}<0.001\right)$, with ICS treatment used by $33 \%$ $(n=19)$ of the group with mild asthma and $79 \%(n=52)$ of the group with moderate-severe asthma, while the remainder did not treat their asthma with ICS during pregnancy. The use of ICS did not affect the already heightened GR hnRNA expression in the mild asthma group. However, within the moderate-severe asthma group, ICS was associated with significantly lower hnRNA expression compared with the no-treatment group $(\mathrm{t}(45)=2.08, \mathrm{p}=0.050)$, but hnRNA levels comparable with the controls (figure 3 ). ICS was not associated with changes to GR total mRNA, GR $\alpha$ mRNA expression or GR $\alpha$ protein levels (figure 3 ).

In the ICS group, both cord blood cortisol and GR hnRNA were positively associated with exon $1 \mathrm{~A} 3$ expression $(r=0.362, p=0.011$ and $r=0.816, p<0.001$, respectively). In this group, the dose of ICS used in the third trimester was negatively correlated with GR hnRNA expression $(r=-0.378, p<0.001)$. In the no-treatment group, no associations were observed between cortisol and hnRNA or exon $1 \mathrm{~A} 3$ expression. Further, the expression of total
Figure 2 The effect of asthma severity on the relative expression of glucorticoid receptor (GR) heterogeneous nuclear RNA (hnRNA), GR exon $1 A 3$ mRNA, GR $\alpha$ mRNA, total GR mRNA and $\mathrm{GR} \alpha$ protein, compared with $\beta$-actin. Values represent the mean ( \pm SEM) of natural logarithmic transformed data. Mod-Sev, moderate-severe asthma; ${ }^{*} \mathrm{p}=0.019$ compared with control and moderate-severe asthma groups. hnRNA and mRNA analysis: control $\mathrm{n}=33$; mild $\mathrm{n}=36$; and moderate-severe $n=47$. $G R \alpha$ protein levels: control $n=17$; mild $n=18$; and moderate-severe $n=20$.

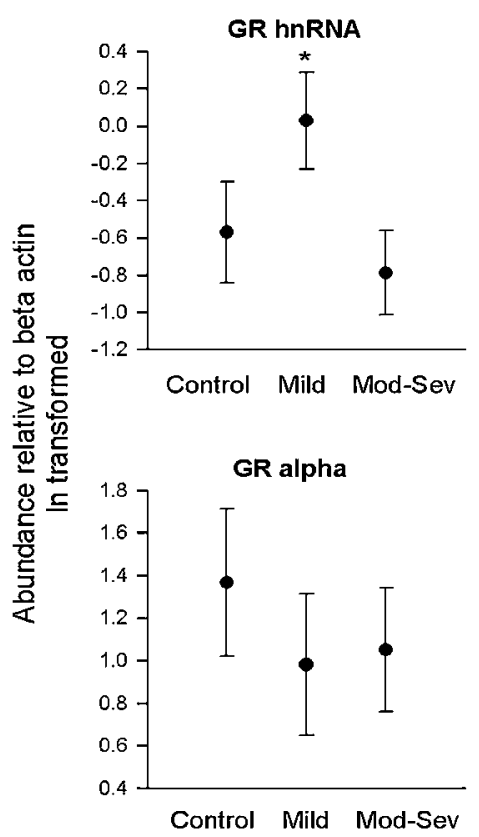

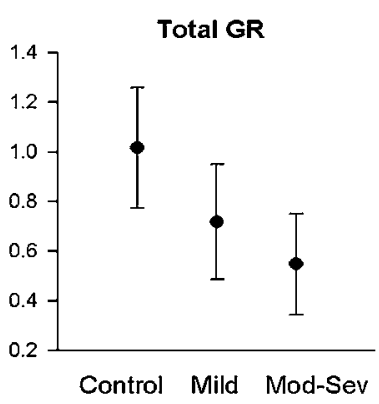

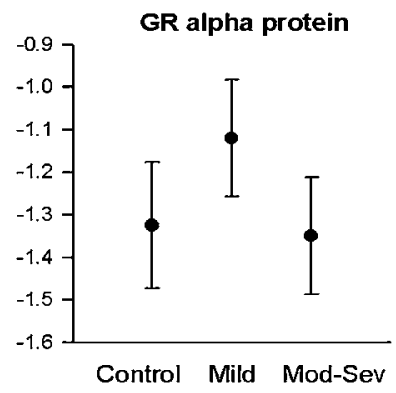


Figure 3 The effect of inhaled corticosteroid (ICS) treatment on glucorticoid receptor (GR) heterogeneous nuclear RNA (hnRNA) expression (top panel) and GR exon $1 \mathrm{~A} 3$ expression (bottom panel) in placentae collected from controls and women with mild or moderate-severe asthma. ${ }^{*} p=0.05$. Control $n=33$, no treatment; mild $n=22$ and moderate-severe $n=10$. ICS, mild $\mathrm{n}=14$ and moderate - severe $\mathrm{n}=37$.

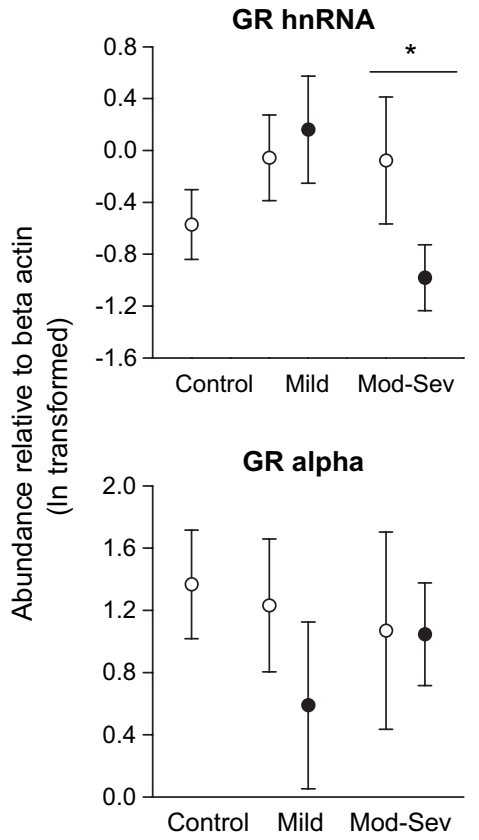

Total GR
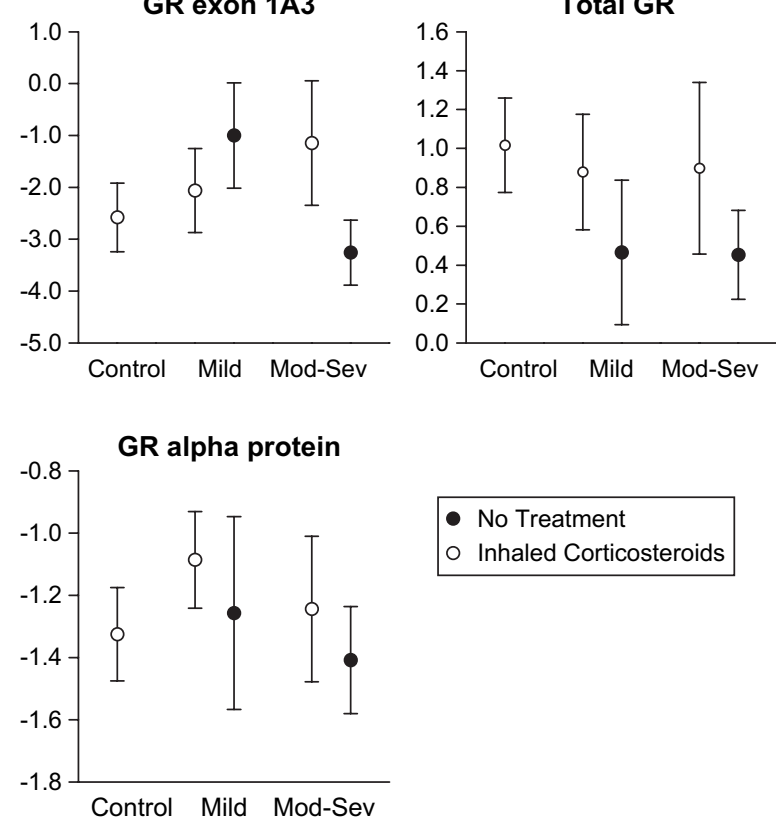

GR mRNA, GR $\alpha$ mRNA and GR $\alpha$ protein levels did not differ between the ICS and no-treatment groups. The dose of ICS used in the third trimester did not correlate with cortisol, GR $\alpha$ mRNA expression, GR $\alpha$ protein levels or birth weight centiles.

\section{The effect of fetal sex on GR gene activity, mRNA expression and protein levels}

Expression levels of total GR mRNA and GR $\alpha$ mRNA in control and asthmatic pregnancies differed according to fetal sex. In females, a significantly higher abundance of total GR mRNA was demonstrated in placentae from the control compared with the asthmatic groups irrespective of asthma severity $(F(1,54)=$ 4.99, $\mathrm{p}=0.003$ ). A similar pattern of abundance was observed with GR $\alpha$ mRNA in the placentae from females; however, this failed to reach statistical significance $(p=0.08)$ (figure 4$)$. In males, the expression of the total placental GR mRNA and GR $\alpha$
mRNA transcripts was unchanged with asthma. Protein levels of GR $\alpha$ were significantly higher in placentae from males compared with females ( $\mathrm{t}(54)=2.385, \mathrm{p}=0.022$; figure 4 ), but did not change with asthma. Placental GR hnRNA and GR 1A3 expression were not independently affected by fetal sex.

The associations between placental expression of hnRNA, 1A3 and cortisol that were observed with ICS were demonstrated to be sex specific. In placentae from males, hnRNA expression was positively correlated with cortisol in both the control and ICS groups $(r=0.594, p=0.005$ and $r=0.474, p=0.003$, respectively) but not the no-treatment group. Expression of exon $1 \mathrm{~A} 3$ was also correlated with cortisol in the ICS group $(r=0.630, p=0.002)$. Expression of both hnRNA and exon 1A3, however, was unaffected by the dose of ICS used in the third trimester. In placentae from females, no correlation was observed between hnRNA expression, exon 1A3 and cortisol in any group. However, third
Figure 4 The effect of fetal sex on heterogeneous nuclear RNA (hnRNA) and mRNA expression and protein levels in placentae from control pregnancies (open circles) or pregnancies complicated by mild asthma (grey circles) or moderate-severe asthma (black circle). Circles represent means ( \pm SEM) of natural logarithmic transformed expression levels compared with $\beta$-actin. $\# \mathrm{p}=0.003$ compared with controls; ${ }^{*} \mathrm{p}=0.02$ compared with males. mRNA analysis: female, control $n=11$, mild $n=16$, moderate-severe $\mathrm{n}=29$; male, control $\mathrm{n}=22$, mild $\mathrm{n}=20$, moderate - severe $\mathrm{n}=18$. Protein analysis: female, control $\mathrm{n}=8$, mild $\mathrm{n}=11$, moderate-severe $n=10$; male, control $n=9$, mild $n=9$, moderate-severe $\mathrm{n}=10$.
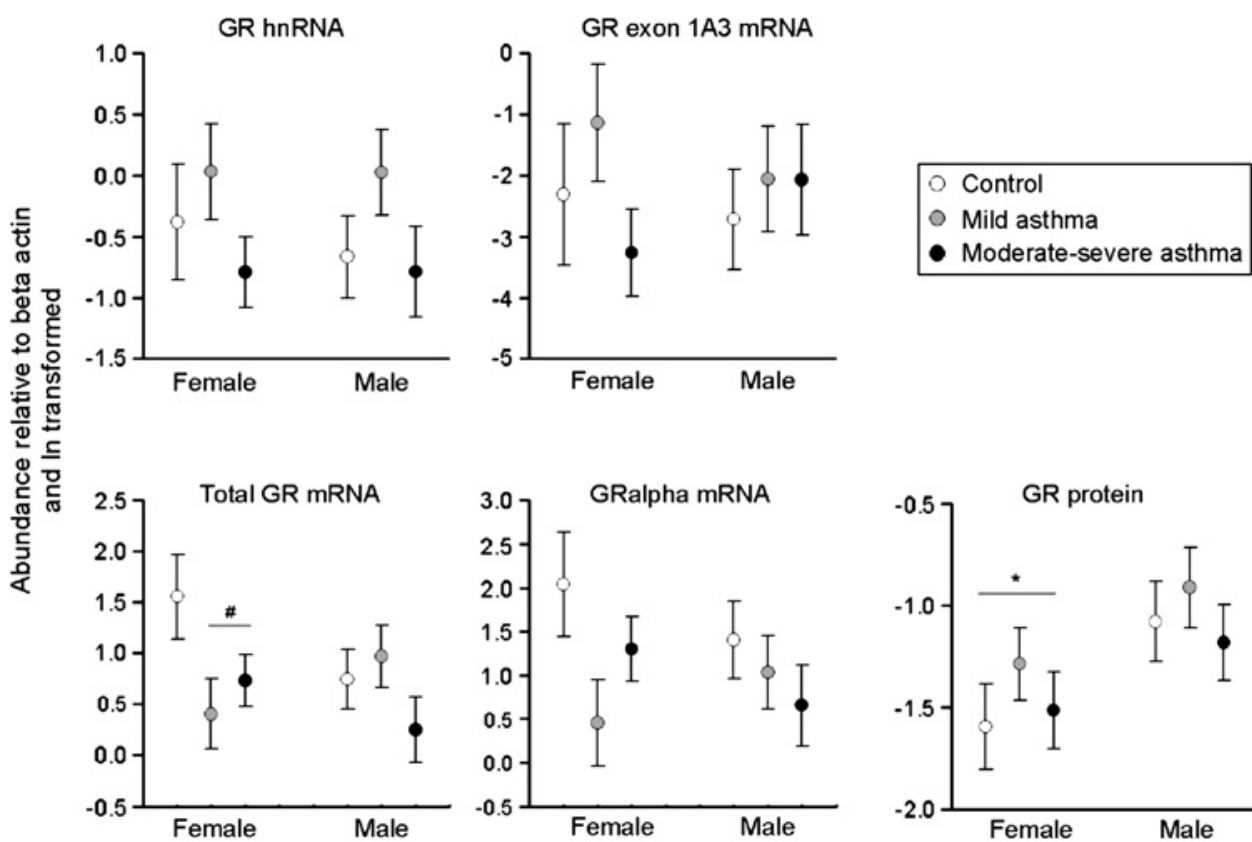
trimester dose of ICS was negatively associated with hnRNA and exon 1A3 expression ( $r=-0.523, p=0.004$ and $r=-0.415$, $\mathrm{p}=0.028$, respectively).

\section{The effect of cigarette smoking on placental GR gene activity, mRNA expression and protein levels}

Smoking was associated with a significant decrease in female birth weight centiles in pregnancies complicated by asthma (smoker, mean $=29.24$, SEM=6.00; non-smoker, mean $=55.82$, $\mathrm{SEM}=3.76$; $\mathrm{t}(69)=3.808, \mathrm{p}<0.001)$; smoking did not affect male birth weight centiles. Cigarette smoking was, however, not associated with changes in GR gene activity, mRNA transcripts or protein levels in placenta from either male or female births (data not shown).

\section{DISCUSSION}

The findings of this work indicate sex-specific alterations to placental GR regulation, cortisol and growth in the presence of asthma. Specifically, female but not male birth weight centiles were inversely associated with cord blood cortisol levels in the presence of maternal asthma; however, concurrent changes to placental GR $\alpha$ protein were not evident. These data suggest that decreased female fetal growth is not due to an increase in glucocorticoid sensitivity via increased GR $\alpha$ protein levels per se.

The comparable GR $\alpha$ protein levels observed in placentae from males and females in both the asthmatic and control groups should predict equal sensitivity to cortisol and similar downstream functional responses. In the males, this held true, with no differences in birth weight centiles apparent between the asthmatic or control groups. However, in the female placentae, GR $\alpha$ protein levels were not predictive of birth weight outcomes. In females, low birth weight centiles occurred with the highest cortisol levels that characterised the group with untreated, moderate-severe asthma. Maternal smoking further reduced female birth weight centiles in this group, while not affecting placental GR $\alpha$ protein levels. These findings suggest a role for an alternative cortisol-mediated pathway in the regulation of female fetal growth. A likely candidate is the insulin-like growth factor (IGF) axis, as increased cortisol is associated with decreased levels of IGF-1 and IGF-binding protein-3 (IGFBP-3) in cases of SGA infants. ${ }^{38}$ Further, in a study of appropriately grown female fetuses in the presence of maternal asthma, we have recently reported increased cord blood IGF-1 concentrations compared with controls, which we have suggested contributes to maintainance of growth in these individuals. In male fetuses, no differences in IGF-1 concentrations or growth were observed between the controls and the groups with asthma. Ongoing work will elucidate whether the IGF axis plays a role in the reductions in female growth that accompany untreated asthma, which we have previously documented. Alternatively, a post-translational modification to female placental GR may occur, which regulates functional outcomes to cortisol. This may occur through phosphorylation of GR protein by p38 mitogen-activated protein kinase (p38MAPK), which has been observed previously in the placenta. ${ }^{39}$ GR phosphorylation in other tissue results in reduced GR binding affinity ${ }^{40}$ and increased nuclear factor- $\kappa \mathrm{B}$ (NF- $\kappa \mathrm{B})$-dependent, proinflammatory cytokine production (for a review, see Rincon and Davis $^{41}$ ). Altered p38MAPK activity with maternal asthma may therefore be an important factor contributing to our current finding of decreased female fetal growth in a high cortisol environment, as well as to our previous report of increased placental proinflammatory cytokine mRNA expression. ${ }^{33}$ Whether p38MAPK activity is altered by asthma or ICS is currently unknown.

Untreated maternal asthma was associated with a high fetal cortisol environment and increased GR gene activity and exon
1A3 mRNA expression in both male and female placentae. These findings suggest that increases in cortisol result in increased GR gene activity, with preferential usage of the exon 1A3 promoter region. Gene activity was restored to control levels when ICS were used to treat asthma. This was particularly evident in female placentae, where an inverse association was observed between the dose of ICS and GR gene activity. Together these data suggest a potential mechanism, in that ICS inhibits maternal cortisol levels resulting in decreased placental exposure to maternal cortisol which leads to decreased placental GR gene transcription. While the mechanisms contributing to increased GR gene activity and 1A3 promoter usage have not been well defined, increased GR 1A3 promoter usage in the presence of cortisol has been reported in leukaemic cell lines. ${ }^{28}$ The current study supports these findings, illustrating that in placental cells, cortisol is associated with an increase in GR gene activity and usage of the GR 1A3 promoter.

Glucocorticoid-dependent suppression of GR expression (ie, homologous downregulation) has been shown to be a mechanism involved in limiting hormone responsiveness. ${ }^{42}{ }^{43}$ The absence of such a mechanism in the male placentae is interesting. It appears that the male placenta does not respond to the presence of a high cortisol environment in the archetypical manner, and instead the placental GR appears cortisol resistant. Consequentially, GR $\alpha$ protein levels in males also remained unaltered from control levels in the presence of asthma, as do the downstream functional effects typically associated with cortisol binding (such as growth and placental cytokine inhibition ${ }^{33}$ ).

Despite significant reductions in GR mRNA in female placentae in the asthma compared with the control groups, no change in GR $\alpha$ protein levels were observed. This may be accounted for by differences in GR $\alpha$ mRNA stability or, alternatively, may result from preferential transcription of other GR isoforms, resulting in differential glucocorticoid sensitivity. We have previously demonstrated decreased mRNA expression of two placental GR isoforms, GR $\alpha$ and GR-P, following in vitro treatment of placentae with the synthetic glucocorticoid dexamethasone, while GR $\beta$ was unaltered. ${ }^{14}$ Given that the GR-P isoform appears to be involved in upregulating GR $\alpha$ activity, ${ }^{17}$ decreased GR-P expression in the presence of asthma-induced increases in cortisol may result in reduced placental glucocorticoid sensitivity. The evidence for glucocorticoid-specific effects on GR isoform-specific transcription is conflicting and appears to be tissue specific. An increased ratio of GR $\alpha$ to GR $\beta$ protein has been demonstrated in dexamethasone-treated nasal polyp tissue in vitro, ${ }^{44}$ while decreased ratios are observed following glucocorticoid exposure of bronchial epithelial cells. ${ }^{45}{ }^{46}$ Further, increased GR $\beta$ to GR $\alpha$ protein ratios have been demonstrated in cases of glucocorticoid insensitivity in a range of inflammatory conditions (asthma, nasal polyps and ulcerative colitis). ${ }^{47-49}$ The sex from which the donor tissue was derived was not included in these studies, but may in part explain the varied results.

The present study has provided insight into sex-specific regulation of the GR in placentae of pregnancies complicated by asthma, characterised by increased endogenous cortisol and the use of exogenous glucocorticoids. This provides a platform to examine further the regulation of placental GR and its downstream effects on cortisol signalling, and may further elucidate determinants of glucocorticoid sensitivity, contributing to our understanding of sex-specific differences in fetal growth in utero. Scientifically, these findings necessitate that any further studies addressing tissue responses to corticosteroids should take into consideration the sex from which the tissue was derived in interpretation of the results. Clinically, 
the findings of this work indicate that male and female growth responses to maternal pathology and/or corticosteroid exposure are sex specific. This in itself warrants further study, as it may have important implications for the clinical management of observed fetal growth alterations in pregnancies complicated by asthma.

Acknowledgements We would like to thank the midwives at the John Hunter Hospital for their generous assistance and support of this study, and all the mothers who kindly donated their placenta.

Funding This work was supported by the National Health and Medical Research Council of Australia (NHMRC, ID 252438 and ID 565347), Asthma Foundation of NSW, the University of Newcastle and the Mothers and Babies Research Centre. Support was also provided from New South Wales Health through the Hunter Medical Research Institute. VLC was the recipient of the Arthur Wilson Memorial Scholarship from the Royal Australian College of Obstetricians and Gynaecologists and an NHMRC Senior Fellowship (ID 510703). VEM was the recipient of a National Health and Medical Research Council Dora Lush (Biomedical) Postgraduate Scholarship and a Hunter Medical Research Institute/Port Waratah Coal Services Postdoctoral Fellowship.

Competing interests $P G$ has received expense reimbursement for lectures given in educational symposia sponsored by GlaxoSmithKline, AstraZeneca and Novartis. He has conducted research sponsored by GlaxoSmithKline and Pharmaxis. The other authors declare no competing interests.

Ethics approval This study was conducted with the approval of the Hunter New England Health and the University of Newcastle Human Research Ethics Committees.

Provenance and peer review Not commissioned; externally peer reviewed.

\section{REFERENCES}

1. Prescott SL, King B, Strong TL, et al. The value of perinatal immune responses in predicting allergic disease at 6 years of age. Allergy 2003;58:1187-94.

2. Prescott SL, Wiltschut $J$, Taylor $A$, et al. Early markers of allergic disease in a primary prevention study using probiotics: 2.5-year follow-up phase. Allergy 2008;63:1481-90

3. Dietert RR, Zelikoff JT. Early-life environment, developmental immunotoxicology, and the risk of pediatric allergic disease including asthma. Birth Defects Res $B$ Dev Reprod Toxicol 2008;83:547-60.

4. Kumar R. Prenatal factors and the development of asthma. Curr Opin Pediatr 2008:20:682-7.

5. Prescott SL, Macaubes C, Yabuhara A, et al. Developing patterns of T cell memory to environmental allergens in the first two years of life. Int Arch Allergy Immunol 1997:113:75-9.

6. Clifton V. Maternal asthma during pregnancy and fetal outcomes: potential mechanisms and possible solutions. Curr Opin Allergy Clin Immunol 2006;6:307-11.

7. Clifton VL. Sexually dimorphic effects of maternal asthma during pregnancy on placental glucocorticoid metabolism and fetal growth. Cell Tissue Res 2005:322:63-71.

8. Clifton VL, Murphy VE. Maternal asthma as a model for examining fetal sex-specific effects on maternal physiology and placental mechanisms that regulate human fetal growth. Placenta 2004;25(Suppl A):S45-52.

9. Murphy VE, Gibson PG, Giles WB, et al. Maternal asthma is associated with reduced female fetal growth. Am J Respir Crit Care Med 2003:168:1317-23.

10. Barker DJP, Eriksson JG, Forsén T, et al. Fetal origins of adult disease: strength of effects and biological basis. Int J Epidemiol 2002;31:1235-9.

11. Seckl JR, Holmes MC. Mechanisms of disease: glucocorticoids, their placenta metabolism and fetal 'programming' of adult pathophysiology. Nat Clin Pract Endocrinol Metab 2007;3:479-88.

12. Murphy VE, Zakar T, Smith R, et al. Reduced 11beta-hydroxysteroid dehydrogenase type 2 activity is associated with decreased birth weight centile in pregnancies complicated by asthma. J Clin Endocrinol Metab 2002;87:1660-8.

13. Lu NZ, Cidlowski JA. The origin and functions of multiple human glucocorticoid receptor isoforms. Ann NY Acad Sci 2004;1024:102-23.

14. Johnson RF, Rennie N. Murphy V, et al. Expression of glucocorticoid receptor mRNA transcripts in the human placenta at term. J Clin Endocrinol Metab 2008;93:4887-93.

15. Pujols L, Mullol J, Torrego A, et al. Glucocorticoid receptors in human airways. Allergy 2004:59:1042-52

16. Pujols L, Mullol J, Picado C. Alpha and beta glucocorticoid receptors: relevance in airway diseases. Curr Allergy Asthma Rep 2007;7:93-9.

17. de Lange $\mathbf{P}$, Segeren $\mathrm{CM}$, Koper JW, et al. Expression in hematological malignancies of a glucocorticoid receptor splice variant that augments glucocorticoid receptor-mediated effects in transfected cells. Cancer Res 2001:61:3937-41.

18. Beger C, Gerdes K, Lauten M, et al. Expression and structural analysis of glucocorticoid receptor isoform gamma in human leukaemia cells using an isoform-specific real-time polymerase chain reaction approach. Br J Haematol 2003:122:245-52.

19. Benediktsson R, Lindsay RS, Noble J, et al. Glucocorticoid exposure in utero: a new model for adult hypertension. Lancet 1993;341:339-41.
20. Dean F, Yu C, Lingas $\mathrm{Rl}$, et al. Prenatal glucocorticoid modifies hypothalamopituitary -adrenal regulation in prepubertal guinea pigs. Neuroendocrinology 2001;73:194-202.

21. Levitt NS, Lindsay RS, Holmes MC, et al. Dexamethasone in the last week of pregnancy attenuates hippocampal glucocorticoid receptor gene expression and elevates blood pressure in the adult offspring in the rat. Neuroendocrinology 1996:64:412-18

22. Moss TJ, Nitsos I, Harding R, et al. Differential effects of maternal and fetal betamethasone injections in late-gestation fetal sheep. J Soc Gynecol Investig 2003;10:474-9.

23. Halasz I, Rittenhouse PA, Zorrilla EP, et al. Sexually dimorphic effects of maternal adrenalectomy on hypothalamic corticotrophin-releasing factor, glucocorticoid receptor and anterior pituitary POMC mRNA levels in rat neonates. Brain Res Dev Brain Res 1997; 100:198-204.

24. Lingas R, Dean F, Matthews SG. Maternal nutrient restriction (48h) modifies brain corticosteroid receptor expression and endocrine function in the fetal guinea pig. Brain Res 1999;846:236-42.

25. Crowther CA, Harding JE. Repeat doses of prenatal corticosteroids for women at risk of preterm birth for preventing neonatal respiratory disease. Cochrane Database Syst Rev 2007:(3):CD003935

26. Bloom SL, Sheffield JS, Mclntire DD, et al. Antenatal dexamethasone and decreased birth weight. Obstet Gynecol 2001:97:485-90.

27. Guinn DA, Atkinson MW, Sullivan L, et al. Single vs weekly courses of antenatal corticosteroids for women at risk of preterm delivery: a randomized controlled trial. JAMA 2001;286:1581-7.

28. Breslin MB, Vedeckis WV. The human glucocorticoid receptor promoter upstream sequences contain binding sites for the ubiquitous transcription factor, Yin Yang 1. J Steroid Biochem Mol Biol 1998:67:369-81.

29. Kapoor U, Tayal G, Mittal SK, et al. Plasma cortisol levels in acute asthma. Indian J Pediatr 2003;70:965-8.

30. Clifton VL, Rennie N, Murphy VE. Effect of inhaled glucocorticoid treatment on placental 11 beta-hydroxysteroid dehydrogenase type 2 activity and neonatal birthweight in pregnancies complicated by asthma. Aust N Z J Obstet Gynaecol 2006:46:136-40.

31. Murphy VE, Gibson PG, Talbot PI, et al. Asthma self-management skills and the use of asthma education during pregnancy. Eur Respir J 2005;26:435-41.

32. Clifton VL, Hodyl NA, Murphy VE, et al. Effect of maternal asthma, inhaled glucocorticoids and cigarette use during pregnancy on the newborn insulin-like growth factor axis. Growth Horm IGF Res 2010:20:39-48.

33. Scott NM, Hodyl NA, Murphy VE, et al. Placental cytokine expression covaries with maternal asthma severity and fetal sex. J Immunol 2009;182:1411-20.

34. Back SE, Waldrop AE, Saladin ME, et al. Effects of gender and cigarette smoking on reactivity to psychological and pharmacological stress provocation. Psychoneuroendocrinology 2008:33:560-8.

35. Kitchen WH, Robinson HP, Dickinson AJ. Revised intrauterine growth curves for an Australian hospital population. Aust Paediatr J 1983;19:157-61.

36. Elferink CJ, Reiners JJ Jr. Quantitative RT-PCR on CYP1A1 heterogeneous nuclear RNA: a surrogate for the in vitro transcription run-on assay. Biotechniques 1996;20:470-7.

37. Delany AM. Measuring transcription of metalloproteinase genes. Nuclear run-off assay vs analysis of hnRNA. Methods Mol Biol 2001:151:321-33.

38. Verkauskiene R, Beltrand J, Claris 0 , et al. Impact of fetal growth restriction on body composition and hormonal status at birth in infants of small and appropriate weight for gestational age. Eur J Endocrinol 2007:157:605-12.

39. Marino VJ, Roguin LP. The granulocyte colony stimulating factor (G-CSF) activates Jak/STAT and MAPK pathways in a trophoblastic cell line. J Cell Biochem 2008:103:1512-23.

40. Irusen E, Matthews JG, Takahashi A, et al. p38 Mitogen-activated protein kinaseinduced glucocorticoid receptor phosphorylation reduces its activity: role in steroidinsensitive asthma. J Allergy Clin Immunol 2002;109:649-57.

41. Rincon M, Davis RJ. Regulation of the immune response by stress-activated protein kinases. Immunol Rev 2009:228:212-24.

42. Schaaf MJ, Cidlowski JA. Molecular mechanisms of glucocorticoid action and resistance. J Steroid Biochem Mol Biol 2002;83:37-48.

43. Wallace AD, Cidlowski JA. Proteasome-mediated glucocorticoid receptor degradation restricts transcriptional signaling by glucocorticoids. J Biol Chem 2001; $276: 42714-21$

44. Pujols L, Alobid I, Benítez P, et al. Regulation of glucocorticoid receptor in nasal polyps by systemic and intranasal glucocorticoids. Allergy 2008;63:1377-86.

45. Korn SH, Wouters EF, Wesseling G, et al. In vitro and in vivo modulation of alphaand beta-glucocorticoid-receptor mRNA in human bronchial epithelium. Am J Respir Crit Care Med 1997;155:1117-22.

46. Pujols L, Mullol J, Pérez M, et al. Expression of the human glucocorticoid receptor alpha and beta isoforms in human respiratory epithelial cells and their regulation by dexamethasone. Am J Respir Cell Mol Biol 2001;24:49-57.

47. Hamid $\mathbf{Q A}$, Wenzel SE, Hauk PJ, et al. Increased glucocorticoid receptor beta in airway cells of glucocorticoid-insensitive asthma. Am J Respir Crit Care Med 1999;159:1600-4.

48. Orii $\mathbf{F}$, Ashida T, Nomura M, et al. Quantitative analysis for human glucocorticoid receptor alpha/beta mRNA in IBD. Biochem Biophys Res Commun 2002;296:1286-94.

49. Torrego A, Pujols L, Roca-Ferrer J, et al. Glucocorticoid receptor isoforms alpha and beta in in vitro cytokine-induced glucocorticoid insensitivity. Am J Respir Crit Care Med 2004;170:420-5. 